\title{
Introduction of Australian Diploid Cotton Genetic Variation into Upland Cotton
}

\author{
L. Ahoton, J.-M. Lacape, J.-P. Baudoin, and G. Mergeai*
}

\begin{abstract}
Genetic barriers often prevent exploiting diploid cotton germplasm for the improvement of tetraploid cotton. The objective of this study was to investigate mating schemes to achieve introgression of Gossypium sturtianum J.H. Willis and G. australe F. Muell diploid cottons into tetraploid G. hirsutum L. Gossypium hirsutum $\times$ G. sturtianum and $G$. hirsutum $\times G$. australe hexaploids were backcrossed to $G$. hirsutum to produce $\mathrm{BC}_{1}$ pentaploids and $\mathrm{BC}_{2}$ and $\mathrm{BC}_{1} \mathrm{~S}_{1}$ euploid and aneuploid plants. The use of $G$. hirsutum $\times G$. australe pentaploids as male parent in backcrosses with $G$. hirsutum allowed the production of an important progeny of $\mathrm{BC}_{2}$ self fertile plants that were euploid or carried one chromosome of $G$. australe in addition to the 52 chromosomes of $G$. hirsutum. The only two $\mathbf{B C}_{2}$ fertile plants issued from $G$. hirsutum $\times G$. sturtianum hybrids were monosomic addition materials. Both of them were obtained with the pentaploid as female parent in the backcross to cv. Stam F. These results confirm that cotton male gametes are more limited than female gametes in the number of supernumerary chromosomes they can carry. This provides a means of developing alien monosomic addition lines in the $G$. hirsutum background from all the diploid species of Gossypium whose chromosomes do not carry genes preventing their individual male transfer. The analysis of the monosomic addition plants produced from the $G$. hirsutum $\times G$. australe hexaploid with simple sequence repeat (SSR) markers allowed us to distinguish seven lines carrying different single chromosomes of $G$. australe. These lines constitute valuable materials with which to carry out fundamental and applied genetic investigations.
\end{abstract}

$\mathrm{H}$ EXAPLOID $\mathrm{F}_{1}$ HYBRID COTTONS from crosses between tetraploid (4x; AADD) G. hirsutum and either diploid $\left(2 x, \mathrm{C}_{1} \mathrm{C}_{1}\right)$ G. sturtianum or $\left(2 x, \mathrm{G}_{2} \mathrm{G}_{2}\right)$ G. australe have desirable agronomic traits such as glandless-seed and glanded-plant, high fiber strength, improved lint fractions, cold and drought tolerance, and possible tolerance or resistance to certain plant pests (Brubaker et al., 1996; Demol et al., 1978; Muramato, 1969; Ndungo et al., 1988). These characters might be used for improving commercial cotton if they could be readily transferred to the genomes of the cultivated types. To reach this goal, hexaploids can be used either directly through recurrent backcrossing to the tetraploid parent (Brown and Menzel, 1950) or indirectly through the development of trispecific allotetraploid hybrids with A- or D-genome diploid bridging species (Deodikar, 1949). The trispecific pathway is interesting because in such allote-

L. Ahoton, Faculté des Sciences Agronomiques, Université Nationale du Bénin, B.P. 526, Cotonou, Republic of Benin; J.-M. Lacape, Centre de Coopération Internationale en Recherche Agronomique pour le Développement (CIRAD), Avenue Agropolis, F-34398, Montpellier Cedex 5, France; J.-P. Baudoin and G. Mergeai, Unité de Phytotechnie tropicale et d'Horticulture, Faculté Universitaire des Sciences Agronomiques, 2 passage des Déportés, B-5030 Gembloux, Belgium. Received 18 Jan. 2002.*Corresponding author (mergeai.g@fsagx.ac.be)

Published in Crop Sci. 43:1999-2005 (2003).

(C) Crop Science Society of America

677 S. Segoe Rd., Madison, WI 53711 USA traploid combinations either the A or the D chromosomes have no autosyndetic partners and theoretically should pair with the chromosomes of the wild Australian species G. sturtianum and G. australe (Mergeai et al., 1998). However, the successful use of AADC or DDAC synthetic tetraploids requires a large effort to produce fertile progeny and to eliminate the undesirable genetic material contributed by the diploid donor and bridge species (Mergeai et al., 1997; Vroh bi et al., 1999). Although the frequency of homeologous recombination between the Australian chromosomes and the A or D chromosomes may be lower in bispecific derivatives than in trispecific derivatives, the bispecific pathway theoretically offers the possibility of generating more progeny in the same amount of time and, thus, to capture more homeologous recombination events. Moreover, in case of direct exploitation of bispecific hybrids through backcrossing the hexaploids to $G$. hirsutum, recombinant chromosomes are far more likely to be incorporated into fertile plants. Because of strong hybridization barriers in the first backcross generation (Dilday, 1986; Muramato, 1969; Altman et al., 1987), the direct exploitation of $G$. hirsutum $\times G$. sturtianum hexaploids is likely to demand more effort than the use of G. hirsutum $\times G$. australe hybrids whose pentaploid derivatives obtained by Brubaker et al. (1999) presented a rather good level of male fertility. The objective of this study was to investigate mating schemes to achieve introgression of $G$. sturtianum and $G$. australe diploid cottons into tetraploid G. hirsutum.

\section{MATERIALS AND METHODS}

First $(6 x / 1)^{1}$ and second $(6 x / 2)^{1}$ generation $G$. hirsutum $\times$ G. sturtianum hexaploids (G3542, G394) ${ }^{2}$ and first $(6 x / 1)^{1}$ and second $(6 x / 2)^{1}$ generation $G$. hirsutum $\times$ G. australe hexaploids (G411, G430) ${ }^{2}$ from Gembloux Agricultural University (GAU) cotton collection (Maréchal, 1983) were backcrossed at Gembloux, Belgium, in 1998 and 1999 to G. hirsutum cultivar Stam $\mathrm{F}$ originating from Togo, West Africa, to produce $\mathrm{BC}_{1}$ pentaploid derivatives. The $\mathrm{G} 354^{2}$ and $\mathrm{G} 394^{2} G$. hirsutum $\times G$. sturtianum hexaploids contain the genomes of $G$. sturtianum accession $\mathrm{G}^{2}{ }^{2}$ and of $G$. hirsutum cv. C2 (G107) ${ }^{2}$ originating from the Democratic Republic of Congo. The G4112 and G430 $G$. hirsutum $\times$ G. australe hexaploids contain the genome of $G$. australe accession $\mathrm{G} 319^{2}$ and of G. hirsutum cv. NC8 (G173) originating from the Democratic Republic of Congo. The first pentaploids obtained from backcrossing these hexaploids to Stam $\mathrm{F}$ and the $G$. hirsutum $\times G$. sturtianum pentaploids already available in the GAU collection (G235, G372) $)^{2}$ were either selfed or backcrossed as male and female parent to Stam $\mathrm{F}$ to produce $\mathrm{BC}_{1} \mathrm{~S}_{1}$ and $\mathrm{BC}_{2}$ seeds at Gembloux in 1999.

${ }^{1}(6 x / 1),(6 x / 2)$ : first and second generation of hexaploid after chromosome doubling.

${ }^{2}$ Accession numbers of seed stock in the GAU cotton collection.

Abbreviations: SSR, simple sequence repeat. 
Table 1. Production of $\mathrm{BC}_{1}$ seeds from synthetic allohexaploids.

\begin{tabular}{|c|c|c|c|c|c|c|c|}
\hline Female parent & Male parent & Pollinations & $\begin{array}{c}\mathrm{BC}_{1} \\
\text { seeds }\end{array}$ & $\begin{array}{c}\text { Seed } \\
\text { pollination }^{-1}\end{array}$ & $\begin{array}{c}\mathrm{BC}_{1} \text { seeds } \\
\text { planted }\end{array}$ & $\begin{array}{c}\mathrm{BC}_{1} \\
\text { plants }\end{array}$ & $\begin{array}{c}\mathrm{BC}_{1} \\
\text { plants }\end{array}$ \\
\hline & & & & - Number - & & - & $\%$ \\
\hline G. hirsutum $\times$ G. sturtianum $(6 x)$ & G. hirsutum cv. Stam f & 63 & 128 & 2.0 & 76 & 38 & 50 \\
\hline G. hirsutum $\times$ G. australe $(6 x)$ & G. hirsutum cv. Stam f & 123 & 202 & 1.6 & 9 & 2 & 22 \\
\hline
\end{tabular}

$\mathrm{G} 235^{2}$ and $\mathrm{G} 372^{2}$ pentaploids were obtained by backcrossing the same hexaploid $\left(\mathrm{G}_{185^{2}}\right)$, issued from a cross between $G$. sturtianum $(\mathrm{G} 4)^{2}$ and G. hirsutum cv. C2 (G107) $)^{2}$, with $\mathrm{C} 2$ and $\mathrm{NC} 8$, respectively. The $\mathrm{BC}_{1}$ pentaploids and a portion of the $\mathrm{BC}_{1} \mathrm{~S}_{1}$ and $\mathrm{BC}_{2}$ hexaploid created in Belgium were grown at Cotonou, Republic of Benin, West Africa, from November 1999 to April 2000 to produce $\mathrm{BC}_{1} \mathrm{~S}_{1}, \mathrm{BC}_{1} \mathrm{~S}_{2}, \mathrm{BC}_{2}$, and $\mathrm{BC}_{2} \mathrm{~S}_{1}$ materials. A portion of some of the $\mathrm{BC}_{2} \mathrm{~S}_{1}$ progenies from $G$. hirsutum $\times G$. australe and $G$. hirsutum $\times G$. sturtianum hexaploids were cultivated at Gembloux in 2000 and 2001. In Belgium, the new materials obtained in the framework of this work were planted each year in early May and cultivated year round in glasshouses under natural light conditions. In Cotonou, plants were cultivated in field conditions.

The backcrossing scheme was accomplished in the following manner. Flowers were emasculated the afternoon before anthesis and the stigma was covered by a small plastic bag. Pollen was applied to stigmas between 0800 and $1100 \mathrm{~h}$ the following morning. To avoid capsule shedding, a small piece of cotton wool containing a drop of the growth regulator solution (100 $\mathrm{mg} \mathrm{L}^{-1}$ naphtoxyacetic acid $+50 \mathrm{mg} \mathrm{L}^{-1}$ gibberellic acid) recommended by Altman (1988) was applied on the ovary just after pollination. Self pollination was forced by clipping the flower bud at candle stage. Hybridization results were pooled by hybrid type to facilitate their interpretation and because no substantial variation among accessions of a same hybrid formula was evident.

Pollen grain fertility was assessed at Gembloux according to two methods, acetocarmine staining ( $15 \mathrm{~g}$ carmine $\mathrm{L}^{-1}$ of acetic acid) and the germination method proposed by Barrow (1981). For both methods, 1000 pollen grains produced from two freshly opened flowers were used. Only large, bright red grains were considered fertile when observed after $30 \mathrm{~min}$ in acetocarmine solution. Any evidence of pollen tube growth was used to identify fertile pollen grains.

Young flower buds were collected between 0800 and $1100 \mathrm{~h}$ according to weather conditions and fixed in fresh Carnoy solution (95\% ethanol-chloroform-glacial acetic acid, 6:3:1, $\mathrm{v} / \mathrm{v} / \mathrm{v})$. The fixing solution was replaced by $70 \%(\mathrm{v} / \mathrm{v})$ ethanol after 48 to $72 \mathrm{~h}$ and the buds stored at $4^{\circ} \mathrm{C}$ until evaluated. Metaphase I squashes were obtained by macerating and grinding with a scalpel a few anthers in a drop of acetocarmine solution on a microscope slide, removing the debris, adding a cover slip, differentiating the chromosomes with mild heat and flattening pollen mother cells with pressure on the cover

Table 2. Pollen fertility of synthetic hexaploid and $\mathrm{BC}_{1}$ pentaploid hybrids.

\begin{tabular}{|c|c|c|}
\hline Genotype & $\begin{array}{c}\text { Stainable } \dagger \\
\text { pollen grains }\end{array}$ & $\begin{array}{c}\text { Germinated } \\
\text { pollen grains }\end{array}$ \\
\hline & 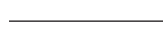 & \\
\hline G. hirsutum cv. Stam f & 97.2 & 95.5 \\
\hline G. sturtianum & 97.4 & 95.4 \\
\hline G. australe & 96.3 & 96.0 \\
\hline G. hirsutum $\times G$. sturtianum $(6 x)$ & 70.2 & 75.6 \\
\hline$G$. hirsutum $\times G$. australe $(6 x)$ & 37.2 & 42.8 \\
\hline G. hirsutum $\times G$. sturtianum $(5 x)$ & 6.0 & 1.0 \\
\hline G. hirsutum $\times G$. australe $(5 x)$ & 15.6 & 19.7 \\
\hline
\end{tabular}

$\dagger$ Acetocarmine stained pollen. slip. Observations were made with a Nikon Eclipse E800 photomicroscope (Nikon, Tokyo, Japan) under oil immersion.

For all the plants analyzed with SSR markers, DNA extractions were performed at Gembloux by the protocol developed by Vroh bi et al. (1996). The SSR markers used to characterize the hexaploid G. hirsutum $\times$ G. australe (G411), its parents, and part of its $\mathrm{BC}_{2} \mathrm{~S}_{1}$ progeny were derived from a repeatenriched cotton genomic library developed by B. Burr at Brookhaven National Laboratory (Upton, NY). Clone sequences used for primer construction are available at http:// demeter.bio.bnl.gov/acecot.html; verified 2 June 2003. The SSR analysis conditions were as described in Risterucci et al. (2000), with a 5' end labeling of the forward primer with $\gamma-\left[{ }^{33} \mathrm{P}\right]$ ATP and a $55^{\circ} \mathrm{C}$ annealing temperature. The SSRs reported were initially chosen for their ability to yield polymorphic PCR products between the two parents of a 'Guazuncho 2' (G. hirsutum) × 'VH8' (G. barbadense L.) $\mathrm{BC}_{1} \mathrm{~F}_{1}$ population, as well as for their mapping position on the tetraploid genetic map (Lacape et al., 2003). Each of the 13 pairs of homeologous $\mathrm{A}$ and D chromosomes of the map were represented by a minimum of three SSRs. Totally, 86 SSRs were tested on 20 DNAs including the first generation following chromosome doubling to form the $G$. hirsutum $\times G$. australe hexaploid, 13 monosomic addition $\mathrm{BC}_{2}$ lines of $G$. australe on G. hirsutum, $G$ australe accession $\mathrm{G} 319$, as well as $\mathrm{C} 2, \mathrm{NC} 8$, and Stam F, and two $\mathrm{BC}_{2} \mathrm{~S}_{1}$ plants carrying 25 bivalents and two univalents.

\section{RESULTS}

Obtaining $\mathrm{BC}_{1}$ pentaploid seeds by backcrossing $G$. hirsutum $\times G$. sturtianum and $G$. hirsutum $\times G$. australe hexaploids with $G$. hirsutum was moderately difficult because these crosses resulted in an average of only 2 and 1.6 seeds, respectively, per pollination (Table 1). Both hexaploid hybrids showed a moderate level of male fertility (Table 2). However, a high proportion of the $\mathrm{BC}_{1}$ seeds produced (50 and $78 \%$, respectively) did not germinate or were empty, lacking a well developed embryo (Table 1).

The $\mathrm{BC}_{1}$ pentaploids of both families grown to reproductive maturity were large robust plants, but to have enough material to carry out our hybridization program, we had to graft 10 scions from the first two G. hirsutum $\times$ G. australe pentaploid plants obtained in 1998 onto cv. NC8 rootstock. The estimates of male fertility using acetocarmine staining and pollen germination gave similar results (Table 2 ). With $15.6 \%$ of pollen grains stained and a pollen grain germination rate of $19.7 \%$, the $G$. hirsutum $\times G$. australe $\mathrm{BC}_{1}$ pentaploid was more fertile than the $G$. hirsutum $\times G$. sturtianum $\mathrm{BC}_{1}$ pentaploid, whose pollen grain stainability and germination rates were only 6 and $1 \%$, respectively. Among the pentaploids, only $0.3 \mathrm{BC}_{2}$ seeds were obtained per pollination when $G$. hirsutum was used as male parent in the backcross. When the pollen of the pentaploids was used in the backcross to Stam F, seed production 
Table 3. Production of $\mathrm{BC}_{2}$ and $\mathrm{BC}_{1} \mathrm{~S}_{1}$ seeds from synthetic $\mathrm{BC}_{1}$ allopentaploids.

\begin{tabular}{|c|c|c|c|c|c|c|c|c|c|}
\hline \multirow[t]{2}{*}{ Female parent } & \multirow[t]{2}{*}{ Male parent } & \multirow[t]{2}{*}{ Pollinations } & \multirow[t]{2}{*}{$\begin{array}{c}\mathrm{BC}_{2} \text { or } \\
\mathrm{BC}_{1} \mathbf{S}_{1} \\
\text { seeds }\end{array}$} & \multirow{2}{*}{$\begin{array}{c}\begin{array}{c}\mathbf{B C}_{2} \text { or } \\
\mathbf{B C}_{1} \mathbf{S}_{1} \text { seeds } \\
\text { pollination }^{-1}\end{array} \\
\text { Number } \\
\end{array}$} & \multirow[t]{2}{*}{$\begin{array}{c}\mathbf{B C}_{2} \text { or } \\
\mathbf{B C}_{1} \mathrm{~S}_{1} \text { seeds } \\
\text { planted } \\
\end{array}$} & \multicolumn{2}{|c|}{$\begin{array}{c}\text { Established } \\
\text { plants from } \\
\mathbf{B C}_{2} \text { or } \\
\mathbf{B C}_{1} \mathrm{~S}_{1} \text { seeds }\end{array}$} & \multicolumn{2}{|c|}{$\begin{array}{c}\text { Self fertile } \\
\text { plants from } \\
\text { established } \\
\mathbf{B C}_{2} \text { or } \\
\mathrm{BC}_{1} \mathrm{~S}_{1} \text { plants }\end{array}$} \\
\hline & & & & & & & $\%$ & Number & $\%$ \\
\hline G. hirsutum $\times$ G. sturtianum $(5 x)$ & G. hirsutum cv. Stam f & 435 & 139 & 0.32 & 56 & 21 & 38 & 2 & 9 \\
\hline G. hirsutum cv. Stam f & G. hirsutum $\times G$. sturtianum $(5 x)$ & 381 & 25 & 0.06 & 8 & 6 & 75 & 6 & 100 \\
\hline G. hirsutum $\times G$. sturtianum $(5 x)$ & G. hirsutum $\times G$. sturtianum $(5 x)$ & 34 & $\mathbf{0}$ & 0.00 & - & - & - & - & - \\
\hline G. hirsutum $\times G$. australe $(5 x)$ & G. hirsutum cv. Stam f & 195 & $\mathbf{5 3}$ & 0.27 & 24 & 10 & 42 & 1 & 10 \\
\hline G. hirsutum cv. Stam f & G. hirsutum $\times G$. australe $(5 x)$ & 807 & 1043 & 1.29 & 366 & 316 & 86 & 310 & 98 \\
\hline G. hirsutum $\times G$. australe $(5 x)$ & G. hirsutum $\times G$. australe $(5 x)$ & 104 & 11 & 0.11 & 11 & 3 & 27 & 0 & 0 \\
\hline
\end{tabular}

was higher with the $G$. hirsutum $\times G$. australe pentaploid (1.3 $\mathrm{BC}_{2}$ seeds per pollination) than with $G$. hirsutum $\times$ G. sturtianum pentaploid $\left(0.1 \mathrm{BC}_{2}\right.$ seeds per pollination). The frequency of successful hybridization was consistent with the respective male fertility levels of both pentaploid hybrids (Table 3 ). No $\mathrm{BC}_{1} \mathrm{~S}_{1}$ seed was produced on selfing the $G$. hirsutum $\times G$. sturtianum pentaploids while a few were obtained when selfing the $G$. hirsutum $\times G$. australe pentaploids $\left(0.1 \mathrm{BC}_{1} \mathrm{~S}_{1}\right.$ seeds per pollination). Because of the risk of after ripening seed dormancy, only $\mathrm{BC}_{1} \mathrm{~S}_{1}$ or $\mathrm{BC}_{2}$ seeds harvested at least $40 \mathrm{~d}$ before the sowing time were planted in Cotonou. The rates of adult plant establishment were much better with the $\mathrm{BC}_{2}$ seeds obtained with $G$. hirsutum as the female parent (Table 3).

Among the $\mathrm{BC}_{2}$ and $\mathrm{BC}_{1} \mathrm{~S}_{1}$ progeny of the two allohexaploids, most of the self fertile plants were $\mathrm{BC}_{2}$ materials produced with the pentaploid as male parent in the backcross with Stam F (Table 3). Only two fertile plants were obtained in the $\mathrm{BC}_{2}$ progeny of the $G$. hirsutum $\times G$. sturtianum pentaploid when it was used as a female parent. These two plants were phenotypically different from each other and from $G$. hirsutum (data not shown). The six other fertile $G$. hirsutum $\times$ $G$. sturtianum $\mathrm{BC}_{2}$ plants, coming from the backcross of the pentaploids to Stam F, were phenotypically similar to $G$. hirsutum. The 311 self-fertile $G$. hirsutum $\times$ $G$. australe $\mathrm{BC}_{2}$ plants were distributed in 18 distinct phenotypic classes. All the plants grouped in a class presented similar qualitative morphological traits (color and shape of the leaves, color of the flowers, relative position of the stigma and the staminal column, size and shape of the capsules). Most of the classes (17 out of 18) came from seeds produced using the pentaploids as male parent and one class came from the backcross to $G$. hirsutum of the pentaploid $G$. hirsutum $\times G$. australe used as female parent. Among these 18 phenotypic classes, the one that presented by far the highest number of individuals (249 plants out of 311) showed a very high level of self-fertility ( $98 \%$ of the control seed production) and qualitative traits similar to those of $G$. hirsutum. Cytogenetic analysis performed in Belgium on the progeny of this class confirmed the euploid nature of these plants $(2 n=4 x=52$ chromosomes $)$. The frequency of appearance and the fertility of the 17 other phenotypic types were variable. The phenotypic segregation observed in the progeny of 13 of the $18 \mathrm{BC}_{2}$ phenotypic classes was coherent with the distribution that is expected to be obtained from monosomic addition stocks. Indeed, in the progeny of these 13 phenotypic classes, three types of individuals were found almost systematically: (i) materials that were phenotypically similar to their mother plant (i.e., putative $4 x+1$ monosomic addition plants with 53 chromosomes), (ii) individuals with a very restricted level of fertility (sterile or producing less than five seeds per plant) showing an accentuation of some of the mother plant traits (i.e., putative $4 x+2$ disomic addition plants, with 54 chromosomes), and (iii) individuals totally similar to G. hirsutum (i.e., putative $4 x$ euploid plants, with 52 chromosomes). The cytological observations performed in Europe on the progeny of these materials confirmed the presence of one additional alien chromosome in all the putative monosomic addition stocks (Fig. 1, Table 4). These 13 monosomic addition lines were designated by $\mathrm{G}_{2}$ followed by a Latin number from I to XIII.

Among the 86 SSRs used to confirm the origin of the supernumerary chromosome of the 13 monosomic addition lines, we found 26 monomorphic SSRs, 28 SSRs from $G$. australe that were absent in all monosomic addition lines, and 32 SSRs that revealed the presence of a $G$. australe specific allo-allele present in at least one monosomic addition line (Fig. 2, Table 5).

The presence of $G$. australe specific SSRs in the monosomic addition lines and the fact that these markers were mapped and assigned to chromosomes or homeologous chromosome pairs of the tetraploid genome led us to infer specific chromosomal assignments for each of the monosomic addition lines. Among the 13 monosomic addition lines we isolated in the $\mathrm{BC}_{2}$ progeny of $G$. hirsutum $\times G$. australe hexaploid, homeologies were

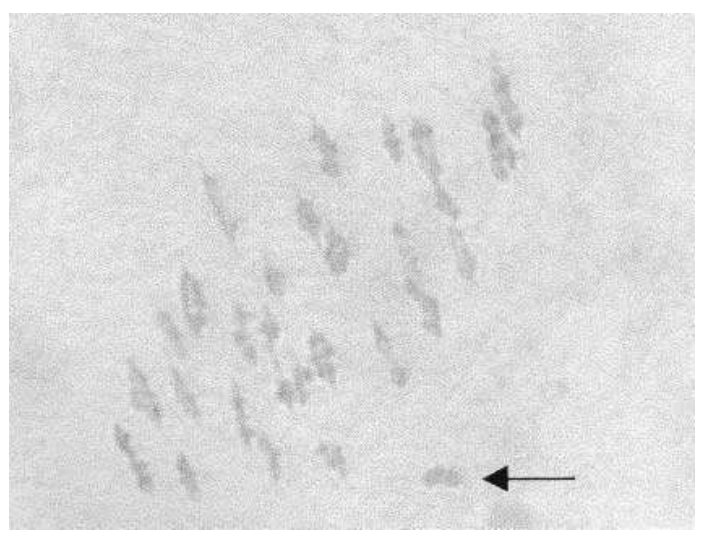

Fig. 1. Meiotic metaphase I cell from plant $G_{2} V(1)$ showing 26 bivalents and one univalent (arrow head). 
Table 4. Results of the cytological observations carried out in the $\mathrm{BC}_{2} \mathrm{~S}_{1}$ progeny of the $G$. hirsutum $\times G$. sturtianum and $G$. hirsutum $\times$ G. australe hexaploids on plants showing the same phenotype as their $\mathrm{BC}_{2}$ parents.

\begin{tabular}{|c|c|c|c|c|}
\hline Genotype $\dagger$ & Chromosome & Univalent & Bivalent & Observed cells \\
\hline & \multicolumn{4}{|c|}{ Number } \\
\hline $\mathbf{C}_{1} \mathbf{I}(\mathbf{1})$ & 53 & 1 & 26 & 5 \\
\hline $\mathrm{C}_{1}$ II (1) & 53 & 1 & 26 & 6 \\
\hline $\mathbf{G}_{2} \mathbf{I}(\mathbf{1})$ & 53 & 1 & 26 & 37 \\
\hline $\mathbf{G}_{2}$ II (1) & 53 & 1 & 26 & 7 \\
\hline G $_{2}$ III (1) & 53 & 1 & 26 & 34 \\
\hline$G_{2} I V(1)$ & 53 & 1 & 26 & 6 \\
\hline$G_{2} V(1)$ & 53 & 1 & 26 & 28 \\
\hline$G_{2}$ VI (11) & 53 & 1 & 26 & 29 \\
\hline$G_{2}$ VII (2) & 53 & 1 & 26 & 5 \\
\hline G.VIII (1) & 53 & $\mathbf{1}$ & 26 & 39 \\
\hline $\mathbf{G}_{2} \mathbf{I X}$ & 53 & 1 & 26 & 31 \\
\hline$G_{2} X(2)$ & 53 & 1 & 26 & 5 \\
\hline $\mathbf{G}_{2} \mathbf{X I}(3)$ & 53 & $\mathbf{1}$ & 26 & 35 \\
\hline $\mathbf{G}_{2} \mathbf{X I I}$ (1) & 53 & 1 & 26 & 6 \\
\hline$G_{2} X I I I$ (2) & 53 & 1 & 26 & 32 \\
\hline
\end{tabular}

† The plants on which cytogenetic analysis were carried out are designated by the symbol of the phenotypic families, followed by the identification number of the plants analyzed in the $\mathrm{BC}_{1} \mathrm{~S}_{1}$ progeny put between parentheses.

found with eight distinct linkage group pairs of the tetraploid genetic map of Lacape et al. (2003). The supernumerary $G$. australe chromosomes of lines $\mathrm{G}_{2} \mathrm{I}, \mathrm{G}_{2} \mathrm{~V}$, and $\mathrm{G}_{2}$ VI present homeology with c10-c20, c12-c26, and c3c17 linkage groups respectively. The line $\mathrm{G}_{2} \mathrm{XII}$ shows specific $G$. australe amplicons that are homeologous with markers mapped on c5-D04 and A01-c18 linkage groups. The two SSR (BNL3029 and BNL852) mapped on c5 and D04 are separated by less than 10 centimorgans (cM) while the three SSR of the A01-c18 pair cover about $75 \%$ of the length of these chromosomes (150 out of $200 \mathrm{cM}$ ) (Lacape et al., 2003). The $\mathrm{G}_{2}$ XII monosomic addition line carries thus the $G$. australe chromosome homeologous to A01-c18 linkage groups and has been introgessed by a fragment of the G. australe chromosome homeologous to c5-D04 pair. The other monosomic addition lines can be assigned to three groups according homeologies inferred by SSRs. Lines $\mathrm{G}_{2} \mathrm{IV}$ and $\mathrm{G}_{2} \mathrm{XI}$ carry the same supernumerary chromosome of $G$. australe that is homeologous to c7-c16 pair. The $G$. australe specific amplicon corresponding to BNL3008 is not present in line $\mathrm{G}_{2} \mathrm{XI}$; this could mean that a part of the $G$. australe supernumerary chromosome was deleted in this line. Lines $\mathrm{G}_{2} \mathrm{II}, \mathrm{G}_{2} \mathrm{VII}, \mathrm{G}_{2} \mathrm{IX}$, and $\mathrm{G}_{2} \mathrm{X}$ carry the same $G$. australe chromosome homeologous to $\mathrm{c} 9-\mathrm{c} 23$ pair (about half of the length of the chromosome is covered by the four SSR markers) (Lacape et al., 2003). For the line $\mathrm{G}_{2} \mathrm{IX}$, the presence of three other SSR markers corresponding to the A02D03 pair, equally covering an important length (130 out of $225 \mathrm{cM}$ ) does not allow to conclude about the type of genetic material exchange that occurred in this material (addition, substitution or recombination). In line $\mathrm{G}_{2} \mathrm{X}$ the $G$. australe specific amplicons corresponding to SSR markers BNL1317 and BNL4053 are not present. This may be due to the deletion of a portion of the supernumerary chromosome of $G$. australe in this line. Lines $\mathrm{G}_{2}$ III, $\mathrm{G}_{2}$ VIII, and $\mathrm{G}_{2}$ XIII show four SSR markers covering the total length of a $G$. australe chromosome that is homoleogous to c6-c25 pair (Lacape et al., 2003). In

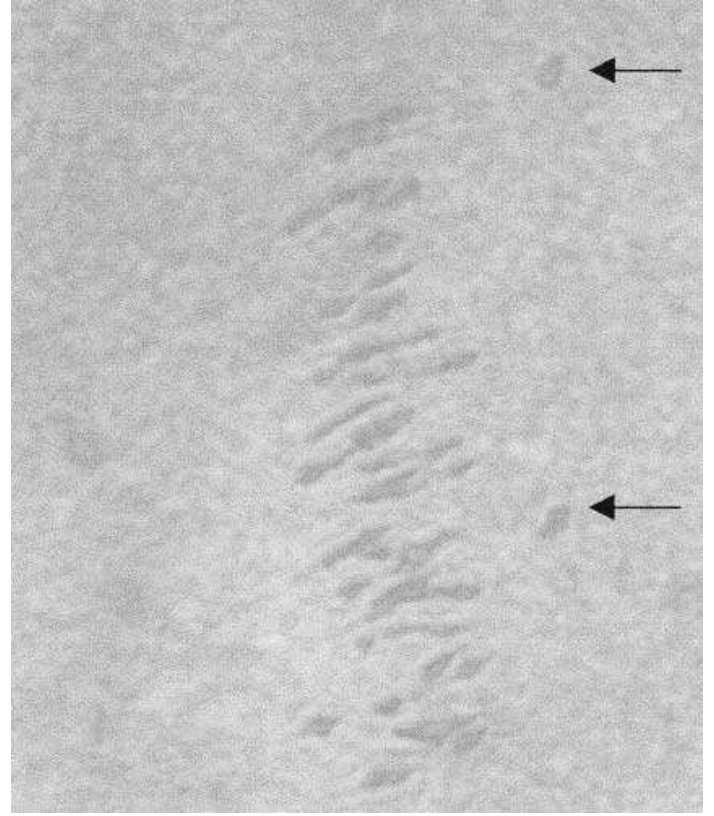

Fig. 2. Meiotic metaphase I cell from plant $\mathbf{G}_{2} X I$ (intro 2) showing 25 bivalents and two univalents (arrow heads).

the line $\mathrm{G}_{2}$ VIII, one can observe an additional homeology with c5-D04 pair (three SSR covering $75 \mathrm{cM}$ in the central part). The case of marker BNL3436, mapped on c25 and present as expected on lines $\mathrm{G}_{2} \mathrm{III}$ and $\mathrm{G}_{2}$ VIII but also on line $\mathrm{G}_{2} \mathrm{~V}$ (homeologous to c12-c26) is probably due to confusion between the alleles of two duplicated loci of same migration (homoplasy). Two plants issued from line $G_{2} X I$ and carrying two univalents (Fig. 3) were designated by symbols $\mathrm{G}_{2} \mathrm{XI}$ (intro1) and $\mathrm{G}_{2} \mathrm{XI}$ (intro2) because they were thought to be introgressed by fragments of the supernumerary chromosome of $\mathrm{G}_{2} \mathrm{XI}$ line. These two plants showed systematically $G$. australe markers found on the line $\mathrm{G}_{2} \mathrm{~V}$ (addition of the homeolog of c12-c26 pair) on the one side, and on lines $\mathrm{G}_{2} \mathrm{II}, \mathrm{G}_{2} \mathrm{VII}$, and $\mathrm{G}_{2} \mathrm{IX}$ (addition of the homeolog of c9-c23 pair), on the other side. These data let us suppose that the plants $\mathrm{G}_{2} \mathrm{XI}$ (intro1) and $\mathrm{G}_{2} \mathrm{XI}$ (intro2) have been the object of a double substitution by two $G$. australe chromosomes homeologous to G. hirsutum chromosomes c9-c23 (4 SSR covering about the half of the chromosome length) and c12-c26 (5 SSR covering 130 out of $180 \mathrm{cM})$. Another hypothesis explaining these results is the substitution of a chromosome of $G$. hirsutum by the homeolog of c12-c26 pair and the recombination of a segment of another chromosome by the homeolog of c9-c23 pair. In both cases, a natural cross must have occurred in Benin between the plant of $\mathrm{G}_{2} \mathrm{XI}$ line that produced these two genotypes and another plant carrying these chromosome fragments in its genome.

The SSR data put in evidence that some of the 13 monosomic addition lines identified in the $\mathrm{BC}_{2}$ progeny of the $G$. hirsutum $\times G$. australe hexaploids carries the same supernumerary $G$. australe chromosome and that some lines were introgressed by fragments of two distinct alien chromosomes. The seven groups for which 
Table 5. Polymorphism observed for 32 G. australe specific mapped SSR markers in the 13 monosomic addition lines issued from $G$. hirsutum $\times G$. australe hexaploids and in two plants presenting 25 bivalents and 2 univalents $\left(G_{2} X I\right.$ intro1 and $G_{2} X I$ intro2).

\begin{tabular}{|c|c|c|c|c|c|c|c|c|c|c|c|c|c|c|c|c|c|}
\hline SSR & $\begin{array}{l}\text { Linkage } \\
\text { groups }\end{array}$ & $\begin{array}{l}\text { Loci } \\
\text { No. }\end{array}$ & $\begin{array}{l}\mathbf{G}_{2} \\
\mathbf{I} \dagger\end{array}$ & $\begin{array}{l}\mathbf{G}_{2} \\
\text { II }\end{array}$ & $\begin{array}{l}\mathbf{G}_{2} \\
\text { III }\end{array}$ & $\begin{array}{l}\mathbf{G}_{2} \\
\mathbf{I V}\end{array}$ & $\begin{array}{l}\mathbf{G}_{2} \\
\mathbf{V}\end{array}$ & $\begin{array}{l}\mathbf{G}_{2} \\
\mathbf{V I}\end{array}$ & $\begin{array}{c}\mathbf{G}_{2} \\
\text { VII }\end{array}$ & $\begin{array}{c}\mathbf{G}_{2} \\
\text { VIII }\end{array}$ & $\begin{array}{l}\mathbf{G}_{2} \\
\mathbf{I X}\end{array}$ & $\begin{array}{l}\mathbf{G}_{2} \\
\mathbf{X}\end{array}$ & $\begin{array}{l}\mathbf{G}_{2} \\
\mathbf{X I}\end{array}$ & $\begin{array}{c}\mathbf{G}_{2} \\
\mathbf{X I I}\end{array}$ & $\underset{\mathbf{X I I I}}{\mathbf{G}_{2}}$ & $\underset{\text { intro1 }}{\mathbf{G}_{2} \mathbf{X I}}$ & $\underset{\text { intro2: }}{\mathbf{G}_{2} \mathbf{X I}}$ \\
\hline 3563 & c10 & 2 & $\mathbf{X}$ & & & & & & & & & & & & & & \\
\hline 3838 & C20 & 1 & $\mathbf{X}$ & & & & & & & & & & & & & & \\
\hline 946 & C20 & 2 & $\mathbf{X}$ & & & & & & & & & & & & & & \\
\hline 3031 & c09-c23 & 2 & & $\mathbf{X}$ & & & & & $\mathbf{X}$ & & $\mathbf{X}$ & $\mathbf{X}$ & & & & $\mathbf{X}$ & $\mathbf{X}$ \\
\hline 2847 & c09 & 1 & & $\mathbf{X}$ & & & & & $\mathbf{X}$ & & $\mathbf{X}$ & $\mathbf{X}$ & & & & $\mathbf{X}$ & $\mathbf{X}$ \\
\hline 1317 & c09-c23 & 2 & & $\mathbf{X}$ & & & & & $\mathbf{X}$ & & $\mathbf{X}$ & & & & & $\mathbf{X}$ & $\mathbf{X}$ \\
\hline 4053 & c09bot-c23 & 2 & & $\mathbf{X}$ & & & & & $\mathbf{X}$ & & $\mathbf{X}$ & & & & & $\mathbf{X}$ & $\mathbf{X}$ \\
\hline 2569 & c06 & 2 & & & $\mathbf{X}$ & & & & & & & & & & $\mathbf{X}$ & & \\
\hline 3436 & c25 & 2 & & & $\mathbf{X}$ & & $\mathbf{X}$ & & & $\mathbf{X}$ & & & & & & $\mathbf{X}$ & $\mathbf{X}$ \\
\hline 3103 & c25 & 2 & & & $\mathbf{X}$ & & & & & $\mathbf{X}$ & & & & & $\mathbf{X}$ & & \\
\hline 2884 & c06 & 1 & & & $\mathbf{X}$ & & & & & $\mathbf{X}$ & & & & & $\mathbf{X}$ & & \\
\hline 1604 & c07 & 2 & & & & $\mathbf{X}$ & & & & & & & $\mathbf{X}$ & & & & \\
\hline 1694 & c07 & 2 & & & & $\mathbf{X}$ & & & & & & & $\mathbf{X}$ & & & & \\
\hline 3008 & c16 & 1 & & & & $\mathbf{X}$ & & & & & & & & & & & \\
\hline 1045 & c12-c26 & 2 & & & & & $\mathbf{X}$ & & & & & & & & & $\mathbf{X}$ & $\mathbf{X}$ \\
\hline 3537 & c26 & 1 & & & & & $\mathbf{X}$ & & & & & & & & & $\mathbf{X}$ & $\mathbf{X}$ \\
\hline 1673 & c12 & 1 & & & & & $\mathbf{X}$ & & & & & & & & & $\mathbf{X}$ & $\mathbf{X}$ \\
\hline 3599 & c12-c26 & 2 & & & & & $\mathbf{X}$ & & & & & & & & & $\mathbf{X}$ & $\mathbf{X}$ \\
\hline 3261 & c12 & $>2$ & & & & & $\mathbf{X}$ & & & & & & & & & $\mathbf{X}$ & $\mathbf{X}$ \\
\hline 834 & c03-c17 & $\mathbf{1}$ & & & & & & $\mathbf{X}$ & & & & & & & & & \\
\hline 3259 & c03-c17 & 2 & & & & & & $\mathbf{X}$ & & & & & & & & & \\
\hline 3029 & c05sup-D04 & 2 & & & & & & & & & & & & $\mathbf{X}$ & & & \\
\hline 852 & c05sup-D04 & 2 & & & & & & & & & & & & $\mathbf{X}$ & & & \\
\hline 2448 & c05-D04 & 2 & & & & & & & & $\mathbf{X}$ & & & & & & & \\
\hline 3992 & c05 & $>\overline{2}$ & & & & & & & & $\mathbf{X}$ & & & & & & & \\
\hline 1671 & D04 & 1 & & & & & & & & $\mathbf{X}$ & & & & & & & \\
\hline 3556 & A02 & 2 & & & & & & & & & $\mathbf{X}$ & & & & & & \\
\hline 3474 & A02-D03 & 2 & & & & & & & & & $\mathbf{X}$ & & & & & & \\
\hline 1646 & A02-D03 & 2 & & & & & & & & & $\mathbf{X}$ & & & & & & \\
\hline 2571 & A01-c18 & 2 & & & & & & & & & & & & $\mathbf{X}$ & & & \\
\hline 3479 & c18 & 2 & & & & & & & & & & & & $\mathbf{X}$ & & & \\
\hline 2652 & A01-c18 & 2 & & & & & & & & & & & & $\mathbf{X}$ & & & \\
\hline
\end{tabular}

$\dagger \mathrm{G}_{2}$ I to $\mathrm{G}_{2}$ XIII: symbolic representation of the 13 different monosomic addition lines isolated from $\boldsymbol{G}$. hirsutum $\times$ G. australe pentaploid. $\leftarrow G_{2} X I$ intro1 and $G_{2} X I$ intro2: sympolic representation of two plants issued from the line G2XI presenting signs of introgression.

the additional chromosome of G. australe has been assigned unequivocally to a pair of $G$. hirsutum homeologs were designated $\mathrm{G}_{2}$, followed by a capital letter (from A to $\mathrm{G}$ ): $\mathrm{G}_{2} \mathrm{~A}$ (line $\mathrm{G}_{2} \mathrm{I}$ ), $\mathrm{G}_{2} \mathrm{~B}$ (lines $\mathrm{G}_{2} \mathrm{II}, \mathrm{G}_{2}$ VII, and $\mathrm{G}_{2} \mathrm{X}$ ), $\mathrm{G}_{2} \mathrm{C}$ (lines $\mathrm{G}_{2}$ III and $\mathrm{G}_{2} \mathrm{XIII}$ ), $\mathrm{G}_{2} \mathrm{D}$ (lines $\mathrm{G}_{2} \mathrm{IV}$ and $\mathrm{G}_{2} \mathrm{XI}$ ), $\mathrm{G}_{2} \mathrm{E}$ (line $\mathrm{G}_{2} \mathrm{~V}$ ), $\mathrm{G}_{2} \mathrm{~F}$ (line $\mathrm{G}_{2} \mathrm{VI}$ ), and $\mathrm{G}_{2} \mathrm{G}$ (line XII). The latter was also introgressed by a small fragment of the $G$. australe homeolog to c5-D04 pair. The line $\mathrm{G}_{2} \mathrm{IX}$, present $G$. australe specific SSR amplicons mapped on c9-23 and A02-D03 pairs of G. hirsutum. It is probable that this line carries a complete supernumerary chromosome of $G$. australe and that it has also been introgressed by a large fragment of another $G$. australe chromosome at the pentaploid stage. It is however impossible with the data gathered so far to assign with certainty the homoelogies between the complete supernumerary chromosome and the introgressed fragment. The line $\mathrm{G}_{2}$ VIII is introgressed by large fragments of chromosomes homeologous to c6-c25 and c5D04 pairs.

\section{DISCUSSION}

As observed by Dilday (1986), Koto (1989), Altman et al. (1987), and Brubaker et al. (1999), obtaining pentaploids from $G$. hirsutum $\times G$. sturtianum and $G$. hirsutum $\times G$. australe hexaploids is easier than producing aneuploid plants from these pentaploids. The success of the latter operation depending on whether the pentaploid plant is selfed or used as male or female parent in backcross with $G$. hirsutum. Our data confirm that the $G$. hirsutum $\times G$. australe pentaploids are more fertile than those obtained from crossing G. hirsutum $\times$ G. sturtianum. We did not observe large differences in the number of seed per cross when we pollinated both pentaploids with $G$. hirsutum pollen, but the success rate when $G$. hirstum $\times G$. australe pentaploid plants were used as male parent in backcrosses to G. hirsutum was better. Similar to Brubaker et al. (1999), we were not able to produce selfed seeds from $G$. hirsutum $\times$ G. sturtianum pentaploids but, unlike Koto (1989), we could with $G$. hirsutum $\times G$. australe materials. The sterility barriers existing in our pentaploid hybrids seemed to be less important than in the materials used by Altman et al. (1987) and embryo rescue was not necessary to produce backcross progeny from both of them.

The use of $G$. hirsutum $\times G$. australe pentaploids as male parent in backcrosses with $G$. hirsutum allowed the production of novel progeny, among which most of the plants exhibited good fertility levels. These self fertile plants were generally euploid $(2 n=4 x=52)$ or carried one chromosome of $G$. australe in addition to the 52 chromosomes of $G$. hirsutum. Similar results were obtained by Koto (1983) with the G. hirsutum $\times G$. longicalyx Hutch. \& Lee pentaploid. On the contrary, the use of both $G$. hirsutum $\times G$. sturtianum and $G$. hirsutum $\times G$. australe pentaploids as female parent in backcrosses with Stam F or when self-pollinated gave rise to plants with low fertility levels. Only two fertile plants were produced from the $G$. hirsutum $\times G$. sturtia- 


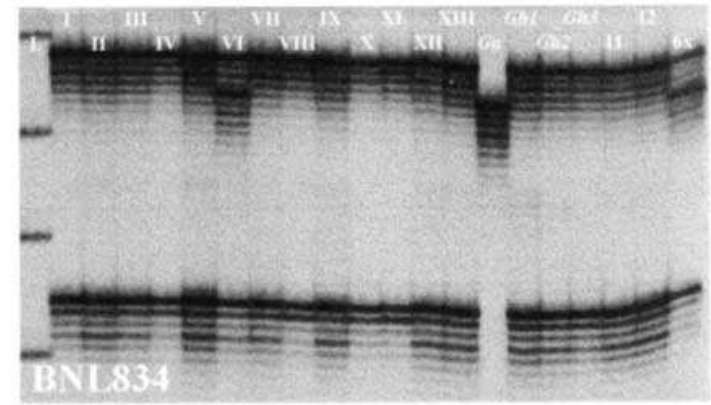

a.

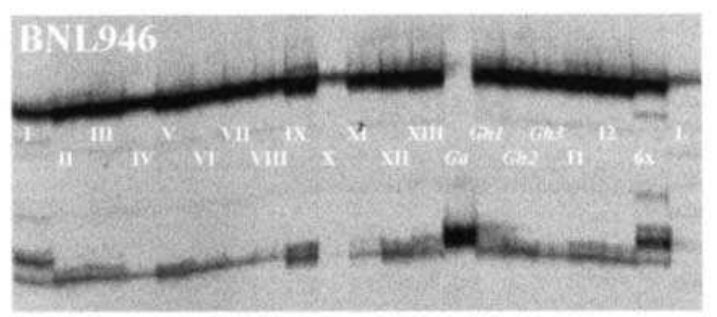

c.

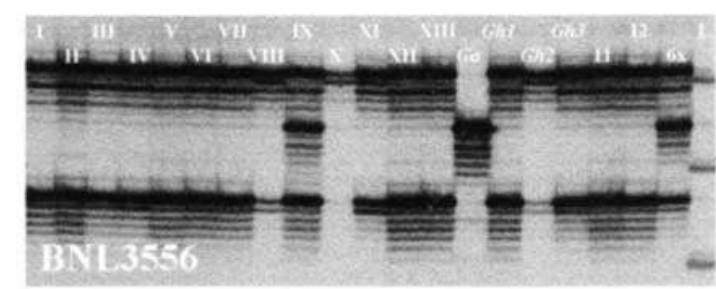

e.

Fig. 3. Gossypium australe specific amplicons polymorphism generated by six SSR markers in the hexaploid $G$. hirsutum $\times$ G. australe, its parents and the 13 monosomic addition BC $_{2}$ lines issued from this hexaploid. I,II,III,IV,V,VI,VII,VIII,IX,X,XI,XII,XIII: phenotypic groups of the 13 monosomic addition plants analyzed. Ga: Gossypium australe, $6 x$ : G. hirsutum $\times$ G. australe hexaploid, Gh1: cv. Stam F G. hirsutum, Gh2: cv. NC8 G. hirsutum, Gh3: cv. C2 G. hirsutum. I1 and I2: G,XI(intro1) and $G_{2} X I($ intro2) plants issued from line G,XI carrying 25 bivalents and 2 univalents. a. BNL834: $G$. australe $(G a)$ co-allele present in line $G_{2}$ VI, b. BNL852: $G a$ co-allele present in line $G_{2} X I I$, c. BNL 946: $G a$ co-allele present in line $G_{2} I, d$. BNL2884: $G a$ co-allele present in lines $G_{2}$ III, $G_{2}$ VIII, and G $G_{2}$ XIII., e. BNL 3556: $G a$ co-allele present in line $G_{2} X I$,., f. BNL 1673: $G a$ co-allele present in line $G_{2} V$.

num pentaploid with the pentaploid as female parent and both of them were monosomic addition materials. The same observation was made by Poisson (1970), André and Verschraege (1984), Koto (1983), Altman et al. (1987), and Brubaker et al. (1999) with bispecific pentaploid hybrids involving $G$. hirsutum and B, C, E, $\mathrm{G}$, or $\mathrm{F}$ genome diploid species. The autosterile plants obtained in the backcrossed progeny of these pentaploids generally carried several alien chromosomes. Our data indirectly confirm the better tolerance of female gametes to multiple alien chromosome addition in their nucleus. They also confirm the observation made by Hau (1981), Koto (1983), Poisson (1970), and Schwendiman (1978) on the better competitiveness of cotton male gametes carrying only one additional alien chromosome compared with pollen grains carrying several alien chromosomes. The behavior of $G$. hirsutum $\times G$. australe hybrid did not conform to the general expectation that in cotton the best crossing successes are obtained when the highest ploidy material was used as the female (Beasley, 1941) and also did not reflect traditional rec- ommendations concerning the critical role of ploidy ratio of endosperm and zygote for successful embryo development (Beasley, 1940; Stephens, 1942). Our results prove that the isolation of a large number of monosomic addition lines from a diploid species in a G. hirsutum background is possible. The use of an adequate growth regulator formula to prevent capsule shedding and an efficient embryo rescue technique may play an important role in success with the most recalcitrant hybrids.

The SSR markers have been very useful to confirm the chromosomic status of the different monosomic addition lines we isolated. Genomic homeologies between G. australe (genome $\mathrm{G}_{2}$ ) chromosomes with those of G. hirsutum (genome $\mathrm{A}_{\mathrm{h}} \mathrm{D}_{\mathrm{h}}$ ) were revealed thanks to the SSR flanking sequences conserved in the two species. The SSR data showed that only seven $G$. australe chromosomes were added in single copies to the G. hirsutum genome among the 13 monosomic addition families we isolated in the $\mathrm{BC}_{2}$ progenies of $G$. hirsutum $\times G$. australe hexaploids. These genetic stocks constitute very valuable materials that can be used for fundamental and 
applied genetic investigations. We plan to use them first to distinguish effects of specific alien chromosomes of $G$. australe and G. sturtianum and then to conduct chromosome specific introgression.

\section{ACKNOWLEDGMENTS}

This work was funded by the contract 2.4536 .99 of the "Fonds de la Recherche fondamentale collective" from Belgium.

\section{REFERENCES}

Altman, D.W., D.M. Stelly, and R.J. Kohel. 1987. Introgression of the glanded-plant and glandless-seed trait from Gossypium sturtianum Willis into cultivated upland cotton using ovule culture. Crop Sci. 27:880-884.

Altman, D.W. 1988. Exogenous hormone applications at pollination for in vitro and in vivo production of cotton interspecific hybrids. Plant Cell Rep. 7:257-261.

André, B., and L. Verschraege. 1984. Amélioration du cotonnier Gossypium hirsutum L. par hybridation interspécifique: Utilisation de l'espèce G. areysianum Delf. Hutch. Bull. Rech. Agron. (Gembloux) 18:151-164.

Barrow, J.R. 1981. A new concept in assessing cotton pollen germinability. Crop Sci. 21:441-444.

Beasley, J.O. 1940. The production of polyploids in Gossypium. J. Hered. 31:39-48.

Beasley, J.O. 1941. Hybridization, cytology and polyploidy of Gossypium. Chron. Bot. 6:394-395.

Brown, M.S., and M.Y. Menzel. 1950. New trispecies hybrids in cotton. J. Hered. 41:291-295.

Brubaker, C.L., C.G. Benson, C. Miller, and D.N. Leach. 1996. Occurrence of terpenoid aldehydes and lysigenous cavities in the glandless seeds of Australian Gossypium species. Aust. J. Bot. 44:601612.

Brubaker C.L., A.H.D. Brown, J. McD. Stewart, M.J. Kilby, and J.P. Grace. 1999. Production of fertile hybrid germplasm with diploid Australian Gossypium species for cotton improvement. Euphytica 108:199-213.

Demol, J., L. Verschraege, and R. Marechal. 1978. Utilisation des espèces sauvages en amélioration cotonnière. Observations sur les caractéristiques technologiques des nouvelles formes allohexaploïdes. Coton Fibres Trop. 33:327-333.

Deodikar, G.B. 1949. Cytogenetic studies on crosses of Gossypium anomalum with cultivated cottons. I. (G. hirsutum $\times$ G. anomalum) doubled $\times$ G. hirsutum. Indian J. Agric. Sci. 19:389-399.

Dilday, R.H. 1986. Development of cotton plant with glandless seeds and glanded foliage and fruiting forms. Crop Sci. 26:639-641.

Hau, B. 1981. Lignées d'addition sur l'espèce G. hirsutum. II. Descrip- tion phénotypique de quelques lignées d'addition monosomique. Coton Fibres Trop. 36:285-296.

Koto, E. 1983. Tentative d'utilisation de l'espèce sauvage diploïde Gossypium longicalyx pour l'amélioration de l'espèce cultivée tétraploïde G. hirsutum L. par la méthode des lignées d'addition et de substitution. Ph.D. thesis. University of Orsay, France.

Koto, E. 1989. Tentative de transfert du caractère "retard à la morphogénèse des glandes à gossypol" I. Caractéristiques des hexaploides $G$. hirsutum $\times G$. sturtianum et $G$. hirsutum $\times G$. australe. En Tome I. 167-173. 1re Conférence de la recherche cotonnière africaine, Lomé, Togo. 31 jan.-2 fév., 1989. IRCT, Montpellier.

Lacape, J.-M., T.-B. Nguyen, S. Thibivilliers, B. Bojinov, E.C. Matz, M. Blewitt, B. Courtois, R.G. Cantrell, B. Burr, and B. Hau B. 2003. First combined RFLP-SSR-AFLP map of tetraploid cotton based on a Gossypium hirsutum $\times$ Gossypium barbadense backcross population. Genome 42:612-626.

Maréchal, R. 1983. A collection of interspecific hybrids of genus Gossypium. Coton Fibres Trop. 38:240-246.

Mergeai, G., J.P. Baudoin, and I. Vroh Bi. 1997. Exploitation of trispecific hybrids to introgress the glandless seed and glanded plant trait of Gossypium sturtianum Willis in G. hirsutum L. Biotech. Agron. Soc. Environ. 1:272-277.

Mergeai, G., I. Vroh Bi, J.P. Baudoin, and P. du Jardin. 1998. Use of randomly amplified polymorphic DNA (RAPD) markers to assist wide hybridization in cotton. p. 121-139. In Y.P.S. Bajaj (ed.) Biotechnology in Agriculture and Forestry, Vol. 42, Cotton. Springer Verlag, Berlin.

Muramato, H. 1969. Hexaploid cotton: Some plant and fiber properties. Crop Sci. 9:27-29.

Ndungo, V., J. Demol, and R. Maréchal. 1988. L'amélioration du cotonnier G. hirsutum L. par hybridation interspécifique. 3. Applications et résultats obtenus. Bull. Rech. Agron. (Gembloux) 23: 283-316.

Poisson, C. 1970. Contribution à l'étude de l'hybridation interspécifique dans le genre Gossypium: Transfert de matériel génétique de l'espèce sauvage diploïde $G$. anomalum à l'espèce cultivée $G$. hirsutum. Ph.D. thesis. University of Orsay, France.

Risterucci, A.M., L. Grivet, J.A.K. N'Goran, I. Pieretti, M.H. Flament, and C. Lanaud. 2000. A high density linkage map of Theobroma cacao L. Theor. Appl. Genet. 101:948-955.

Schwendiman, J. 1978. L'amélioration du cotonnier Gossypium hirsutum par hybridation interspécifique: Utilisation des espèces $G$. barbadense et G. stocksii. Ph.D. thesis. University of Orsay, France.

Stephens, S.G. 1942. Colchicine-produced polyploids in Gossypium I. An autotetraploid Asiatic cotton and certain of its hybrid with diploid species. J. Genet. 44:272-295.

Vroh bi, I., A. Maquet, J.P. Baudoin, P. du Jardin, J.M. Jacquemin, and G. Mergeai. 1999. Breeding for "low-gossypol seed and highgossypol plants" in upland cotton. Analysis of tri-species hybrids and backcross progenies using AFLP and mapped RFLPs. Theor Appl Genet. 99:1233-1244. 